\title{
Relation between Global Solar Radiation and Solar Ultraviolet Radiation in Different Parts of Nepal
}

\author{
Rudra P. Pokhrel ${ }^{1 *}$, Binod K. Bhattarai ${ }^{2}$ \\ ${ }^{1}$ Central Department of Physics, Tribhuvan University, Kathmandu \\ ${ }^{2}$ Institute of Engineering, Tribhuvan University, Pulchowk, Lalitpur
}

\begin{abstract}
Part of the solar spectrum whose wavelength lies between 40 to $400 \mathrm{~nm}$ is called Solar Ultraviolet radiation. Solar UV Index (UVI) is the measure of the UV radiation level at a place, which plays the important role to raise public awareness and alert people to use protective measures when exposed to UV radiation. This study tries to find out the UV radiation level at a place by knowing the global radiation and will help to find out the UV radiation level at different places where UV radiation measuring instruments are not easily accessible. By the study of the relationship between global solar radiation and Solar Ultraviolet radiation at different sites (Biratnagar, Lukla, Kathmandu and Pokhara) of Nepal, simple regression equations were obtained. UV radiation level at a place was retrieved by using this equation. Ground based global solar radiation were measured by using radiation measuring instrument, Pyranometer (CMP6), manufactured by Kipp and Zonen, Netherland. A comparison between equation based calculation and ground based measurement of UV level (using NLU-UV meter) shows the average deviation of $3 \%$ at Lukla, 7\% at Kathmandu and Pokhara and 6\% Biratnagar in the year 2009 and 2010. It is also noted that Lukla is clearer among the four stations. This deviation might be due to effect of aerosols, humidity and non-ideal cosine response of the instrument.
\end{abstract}

\section{Introduction}

Sun emits wide band of radiation of different wavelengths. Band of solar radiation whose wavelength lies between $40 \mathrm{~nm}$ to $400 \mathrm{~nm}$ is called solar ultraviolet radiation. The atmospheric gases, especially $\mathrm{N}_{2}, \mathrm{O}_{2}$ and $\mathrm{O}_{3}$ efficiently absorb the most harmful UV radiation. Only about 10$30 \%$ of the UV-B $(280 \mathrm{~nm}-315 \mathrm{~nm})$ and most of the UV-A $(315 \mathrm{~nm}-400 \mathrm{~nm})$ radiation reaches the earth's surface where as UV-C (200 nm $-280 \mathrm{~nm})$ is completely absorbed by ozone (Dhakal K. P, 2009). Photo biological reactions caused by surface solar UV radiation are mostly harmful for living things. The surface solar UV radiation causes human health problems such as skin cancer, eye damage, premature aging of the skin etc. and also damage to animals, plants, microorganisms as well as the non living things (WHO, 2008) For last two decades, the global increase in UV intensity on the earth surface due to stratospheric ozone layer depletion due to anthropogenic means (mostly due to excessive use of chlorofluorocarbons) became an issue of public concern. The increase in intensity of UV radiation on the earth surface strongly affects the living and non living things (Krotkov et al, 1998). So it is very important to make an estimation of surface UV radiation to establish the global climatologies of UV radiation and its trends due to stratospheric ozone layer depletion and other means. There are various methods to estimate the surface UV radiation. The methods include satellite estimation, such as Ozone Monitoring Instrument (OMI), Mathematical calculation, example Libradtran model based on Stamnes et al (1988) and Ground based measurement. Ground based measurement can be carried out using different types of measuring instruments like Brondband instrument, Spectroradiometer, 
Multifilter broad band radiometer (Gelsor, 2004). Among these methods Ground based measurement is the best. But due to lack of high quality ground based UV instrument on various places satellite measurement and mathematical model are needed to estimate the daily global distribution of UV irradiance. However it is important that the satellite estimates of surface UV irradiance are validated under the various set of conditions (Kalliskota et al., 2000).

In this work a comparison between UV dose measured by multifilter broad band radiometer (NILU-UV meter) and Global solar irradiance by broad band instrument (Pyranometer) is made. Global solar irradiance at the ground level is measured by Pyranometer manufacture by Kipp and Zonen Netherlands. The solar radiation spectrum reaching the earth surface extends approximately from 300 to 2,800 $\mathrm{nm}$. The Pyranometer used in this work is CMP6 with range between 310 to 2,800 $\mathrm{nm}$ (Kipp and Zonen, 2006). Solar UV dose at ground level is measured by NILU-UV meter manufacture by the Norwegian Institute for Air research (NILU). This instrument has six filters, five in the UV and one in the visible wavelength region. Band width of each channel is about $10 \mathrm{~nm}$ with central wavelengths at $302,312,320,340,380 \mathrm{~nm}$ and the sixth channel measures photosynthetic active radiation in the wavelength region $400-700 \mathrm{~nm}$ (NILU, 2008).

\section{Methodology}

In this work, two types of data sets are analyzed. These are the data from ground based measurement with NILU-UV meter and Pyranometer. Both the instruments (NILU-UV meter and Pyranometer) were installed on the four sites. Each of the NILU-UV meter and Pyranometer has been named with a serial number provided by the manufacturer. The selected sites and serial number for used instrument are given in table 1.

Table 1: Selected sites

\begin{tabular}{|l|c|c|c|c|c|}
\hline \multicolumn{1}{|c|}{ Sites } & Latitude & Longitude & Altitude & $\begin{array}{c}\text { NILU Serial } \\
\text { Number }\end{array}$ & $\begin{array}{c}\text { Pyranomet } \\
\text { er } \\
\text { Serial } \\
\text { Number }\end{array}$ \\
\hline Biratnagar (BRT) & $26^{\circ} 27^{\prime} \mathrm{N}$ & $87^{\circ} 6^{\prime} \mathrm{E}$ & $72 \mathrm{~m}$ & NILU-UV 133 & CMP6 643 \\
\hline Kathmandu (KTM) & $27^{\circ} 43^{\prime} \mathrm{N}$ & $85^{\circ} 18^{\prime} \mathrm{E}$ & $1350 \mathrm{~m}$ & NILU-UV 136 & CMP6 645 \\
\hline Pokhara (PKR) & $28^{\circ} 13^{\prime} \mathrm{N}$ & $83^{\circ} 58^{\prime} \mathrm{E}$ & $827 \mathrm{~m}$ & NILU-UV 137 & CMP6 646 \\
\hline Lukla (LKL) & $27^{\circ} 41^{\prime} \mathrm{N}$ & $86^{\circ} 44^{\prime} \mathrm{E}$ & $2850 \mathrm{~m}$ & NILU-UV 135 & CMP6 644 \\
\hline
\end{tabular}

NILU-UV meter and Pyranometer can store one minute average UV and irradiance data for few days. So stored data are downloaded to computer and different computing programs are made to read the UV data and total irradiance data. The extracted data from the NILU-UV meter is in the unit of energy per unit area $\left(\mathrm{W} / \mathrm{m}^{2}\right)$ which is converted in to UV index as described by Dahlback (1996). The data are analyzed from 13 August 2009 to 31 May 2010 for Biratnagar, Kathmandu and Pokhara whereas for Lukla, it is from 4 October 2009 to 31 May 2010 because of late installment of the instrument. 


\section{Result and discussions}

The cloud free days are selected and graph is plotted between the UV index and irradiance. The corresponding UV index and irradiance are taken for every half an hour interval to make the graph clearer. From these plots the best fitted second order polynomials are obtained for each sites, which are used to calculate the UV index at that place by using the Global solar irradiance value later. The graph between UV index and irradiance for Lukla is shown in the Figure 1. The solid line represents the best fitted quadratic trend line.

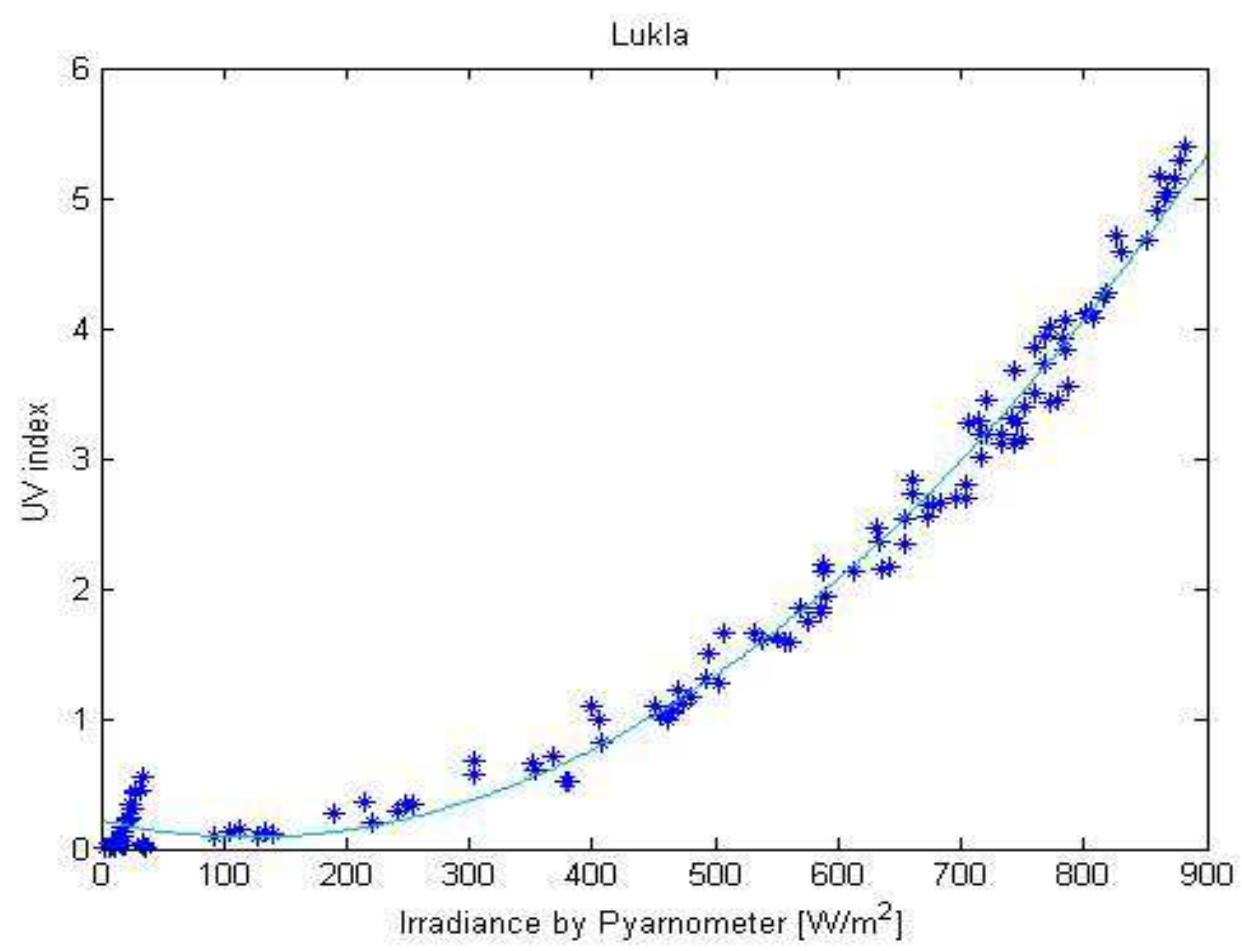

Figure 1: Plot of irradiance and UV index for Lukla station.

The equation of best fitted quadratic trend line is

$$
y=8.6 \times 10^{-6} x^{2}-0.0021 x+0.22
$$

Similar equations are found for other sites.

Although the UV radiation level at a place is greatly affected by the concentration of ozone layer on the stratosphere, it was ignored in this study. Regression equations were used to find out the UV index at a particular time by using the irradiance at the same time. Thus, the UV index obtained by using equation for an interval of 30 minutes are used to compare ground based result obtained by using NILU-UV meter for the respective days.

Figure 2(a) and 2(b) represent the variation of UV indices with time (UT) on 10 November 2009 and 8 March 2010 respectively for Lukla station. The solid line represents the UV index value calculated by passive method and the dotted line represents that measured by the ground based instrument. The UV index obtained from passive method is about an average $0.2 \%$ higher than that of ground based measurement on 10 November 2009. On 8 March, the ground based 
measurement is higher than the passive method by an average value of 5\%. Results show that there is good agreement on the value of UV index calculated from Pyranometer and NILU-UV meter.

a
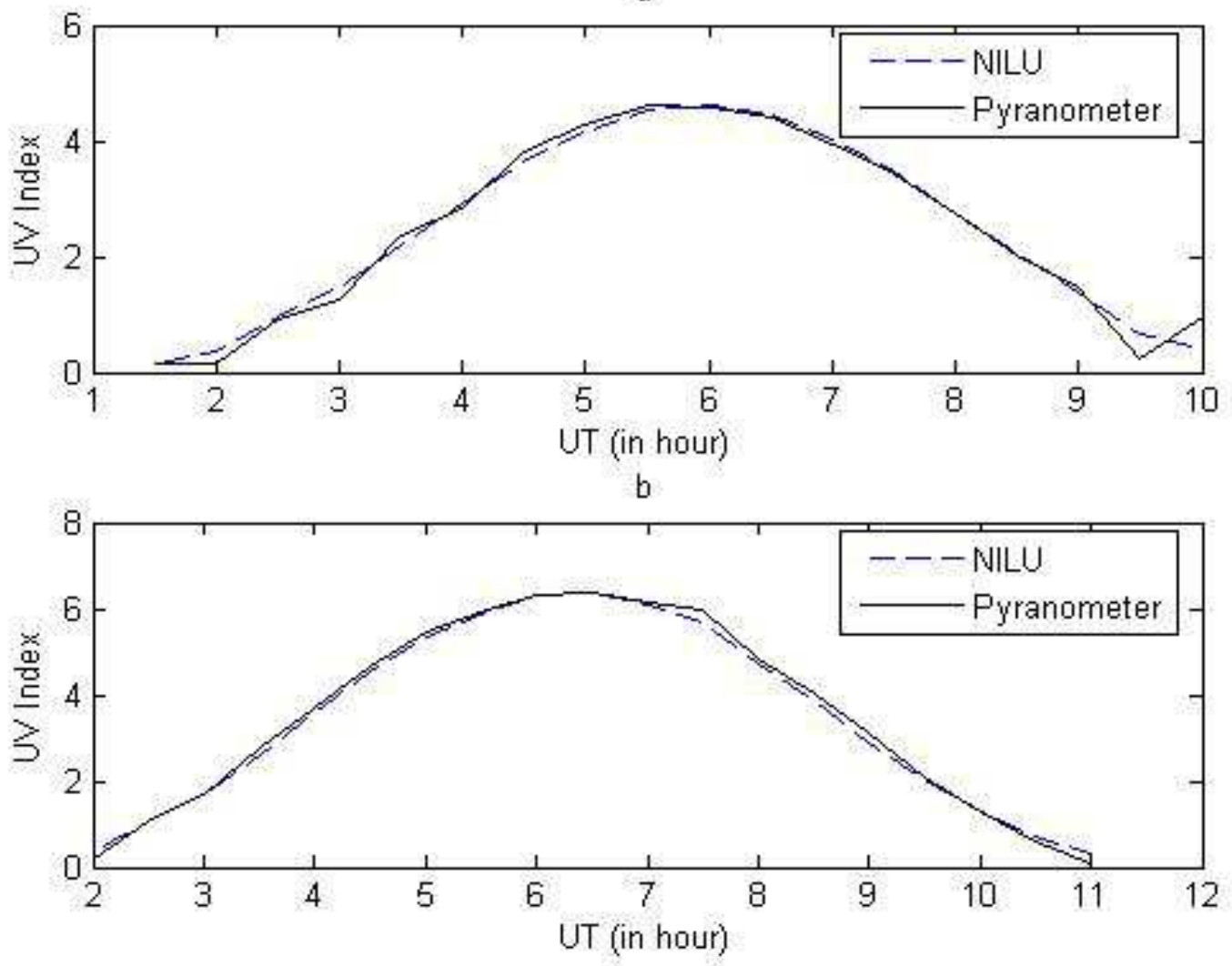

Figure 2: Variation of UV index with time during 10 November and 8 March.

However in the morning and the late afternoon, there is higher deviation in two methods in Lukla. This higher value of deviation might be due to the presence of water vapor on the atmosphere because Lukla is mountainous region. The correlation coefficient (r) between the passive method and ground based measurement is found to be 0.9920 and 0.9986 respectively on10 November 2009 and 8 March 2010.

The trend of UV index with time on the 20 December 2009 and 19 February 2010 are shown in the Figure 3(a) and 3(b) respectively for Kathmandu. From Figure 3(a) and 3(b), we can conclude that the days are highly influenced by meteorological change during the day time. There is sudden drop on the value of UV index about UT 7 on both days. This might be due to the sort moment cirrus cloud on atmosphere. 
a

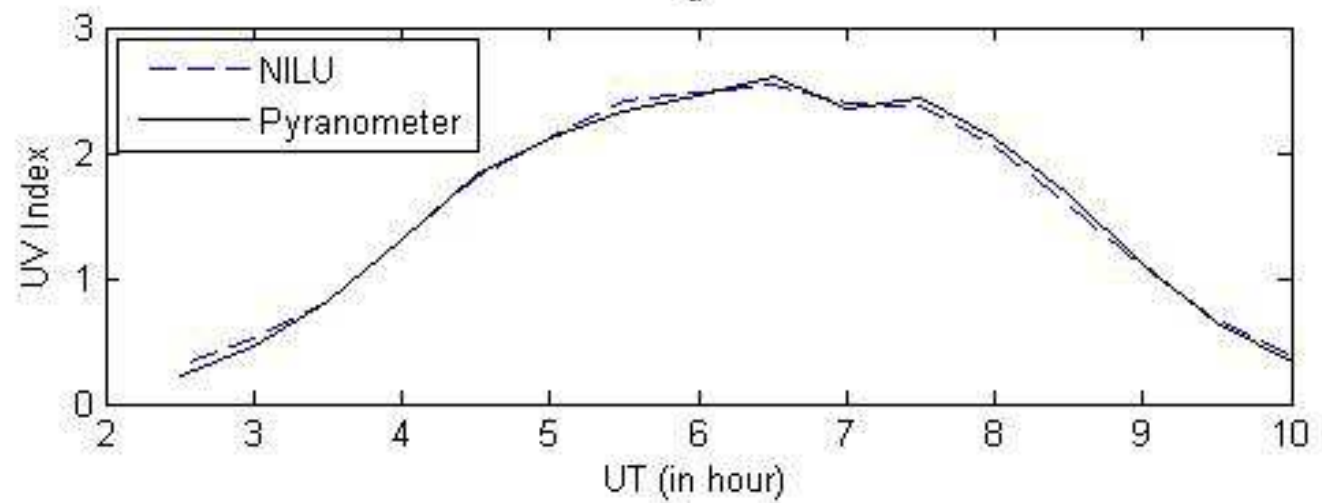

b

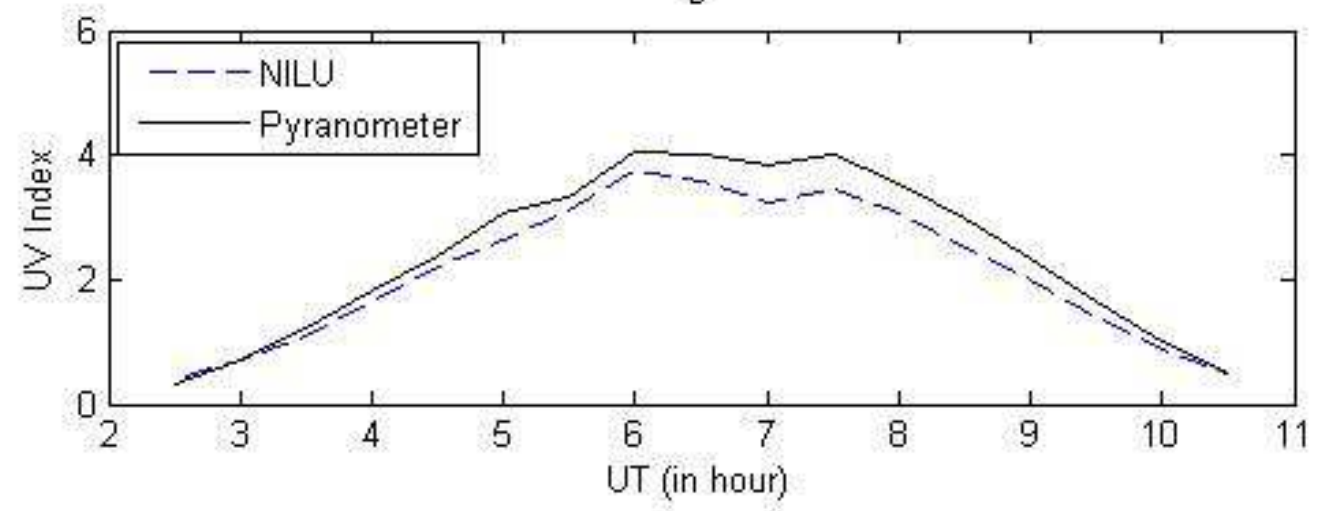

Figure 3: Trend of UV index with time during 20 December 2009 and 19 February 2010.

On December 20 Pyranometer gives the value of UV index less than that of ground based measurement. The difference is about 3\% on average. On 19 February measurement from Pyranometer is about $10 \%$ higher than that of ground based method. However a High degree correlation is found. The correlation coefficient ( $r$ ) between two methods is 0.9983 and 0.9962 for December 20 and February 19 respectively.

Subplot 4 (a) and 4 (b) represent the diurnal variation of UV indices on 16 October 2009 and 1 April 2010 respectively for Pokhara. On these days both methods are in good agreement. The solid curve represents the curve of UV index obtained from passive method and the dotted curve represents the ground based measurement. In both days, there is high percentage difference between two measurements after noon time than that before solar noon. The larger difference after noon time might be due to the presence of cloud on atmosphere or due to increase in different types of pollution and dust particles on the atmosphere after noon time. The average percentage difference between two methods is about $7 \%$ and $6 \%$ on 16 October and 1 April respectively. The correlation coefficient (r) between the two measurements is 0.9953 and 0.9962 respectively. 

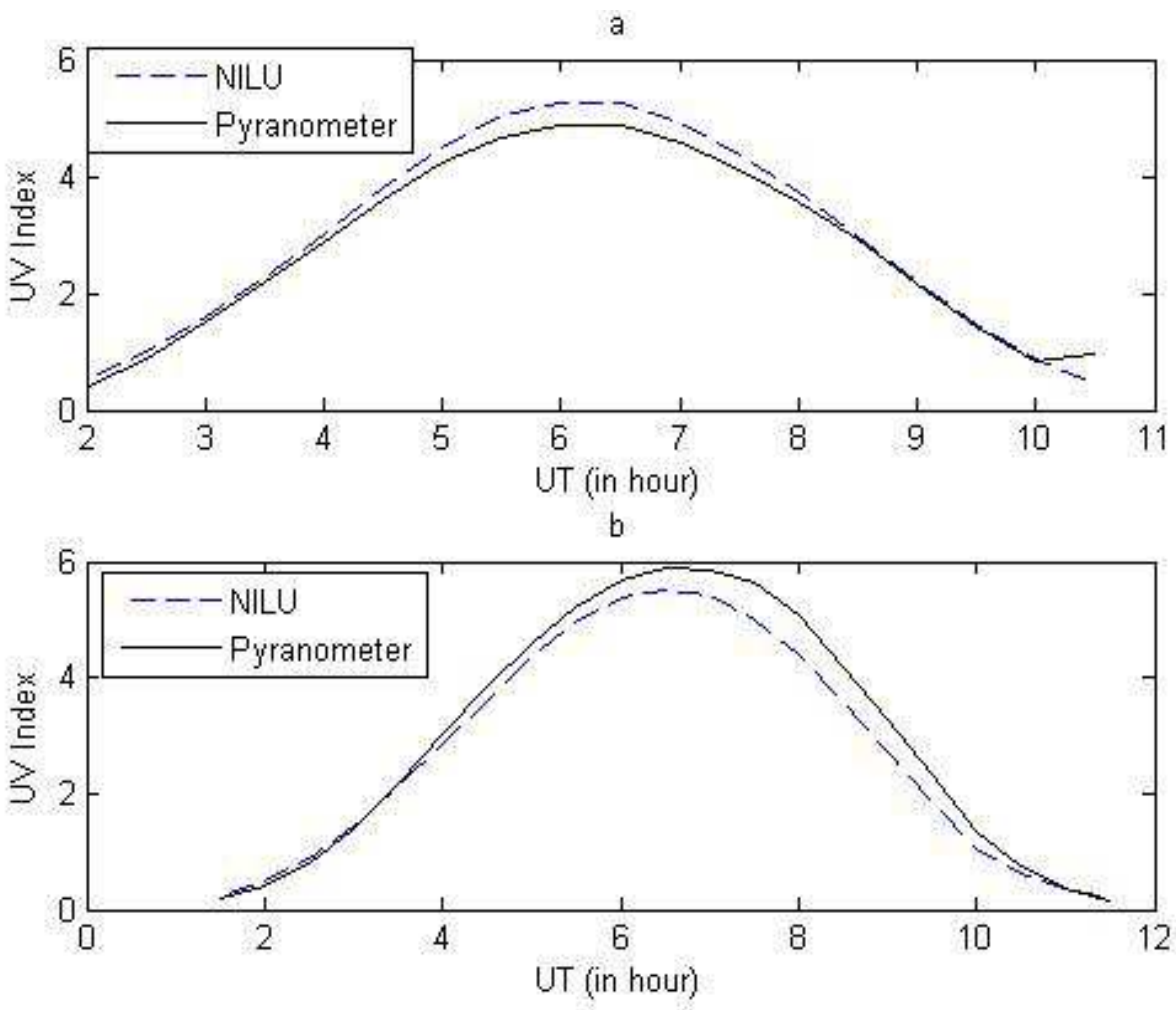

Figure 4: Diurnal variation of UV indices on 16 October 2009 and 1 April 2010.
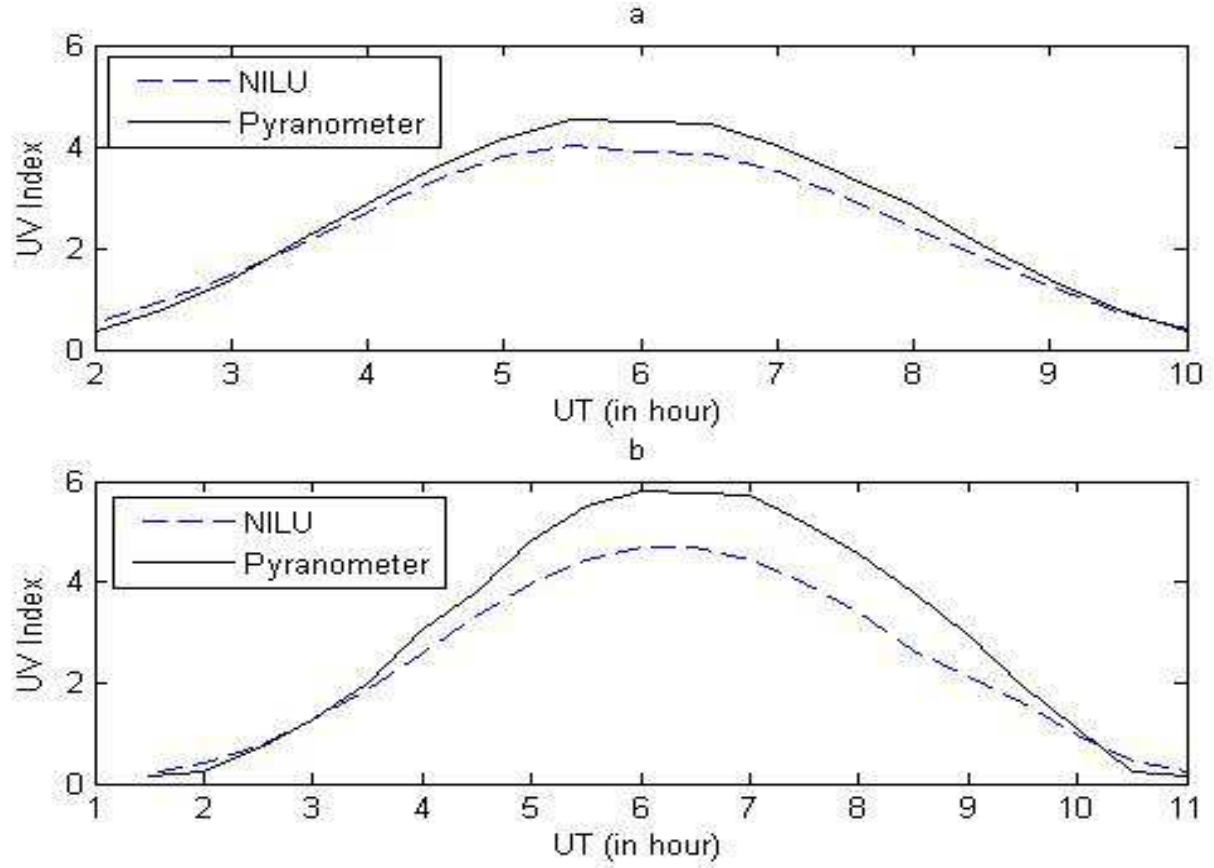

Figure 5: Trend of UV indices on 29 October 2009 and 28 March 2010. 
Trend of UV indices for Biratnagar on 29 October 2009 and 28 March 2010 are shown in the Figure 5(a) and 5(b) respectively. The average value of UV index measured by passive method is greater than that of ground based measurement on both days of consideration. Deviation is more at day time than that of morning and evening. This large difference on day time can be attributed to the effect of increase in pollution level due to industrial, vehicular and human activity. Since Biratnagar is densely populated, emission of high level of aerosols including different pollution and dust particles deviate the actual value UV indices reaching the earth surface. The average percentage difference between two measurements is about $4 \%$ and $8 \%$ on 29 October and 28 March respectively.

\section{Conclusion}

We have demonstrated that with the knowledge of Global solar radiation at a place, we can estimate the UV index value. The percentage difference ranges from $\sim 3 \%$ at Lukla, $\sim 7 \%$ at Kathmandu and Pokhara and $\sim 6 \%$ Biratnagar. These errors are caused mainly due to ignorance of ozone concentration and other facts like aerosols, humidity and non-ideal cosine response of the instrument. Since error occur mainly early in the morning and late afternoon, the midday UV index level and long term trends can be derived with much accuracy.

\section{Acknowledgement}

We are thankful to Solar Radiation and Aerosol in Himalaya Region (SAHR) for providing the data of NILU-UV meter and Pyranometer that are used in this study.

\section{REFERENCES}

[1] Dahlback A., Measurements of biologically effective UV doses, total ozone abundances, and cloud effects with multichannel, moderate bandwidth filter instruments. Applied Optics 35 (33), 6514-6521, 1996.

[2] Dhakal K. P, Modeling clear sky solar Ultraviolet radiation and its comparison with ground based measurement in Kathmandu, (M.Sc. thesis), Central department of Physics Tribhuvan University, 2009.

[3] Gelsor N., Studies on solar Ultraviolet radiation and ozone over the Tibetan plateau, $\mathrm{PhD}$ thesis, University of Bergen, Norway, 2004.

[4] Kalliskota S., Comparison of daily UV doses estimated from Nimbus 7/TOMS Measurements and ground-based spectroradiometric data, Journal of Geophysical Research, 106, D4, 2000.

[5] Kipp and Zonen, CMP series instruction manual, Kipp and Zonen B.V., Delftech park 36, Netherlands, 2006. 
[6] Krotkov N. A., Satellite estimation of spectral surface UV irradiance in the presence of tropospheric aerosols, Journal of Geophysical Research, 103, D8, 1998.

[7] The NILU-UV Irradiance Meter, User's Manual, Version 2.1.NILU Products AS. Kjeller, Norway. www.nilu.no/products. ISBN 978-82-425-1978-8, 2008.

[8] WHO, Global UV Index practical guide, 2008. 